\section{Synchronous learning and asynchronous learning during COVID-19 pandemic: a case study in India}

\author{
Cassandra Jane Fernandez, Rachana Ramesh and \\ Anand Shankar Raja Manivannan \\ Commerce, Christ University, Bangalore, India
}

Synchronous

learning and

asynchronous

learning

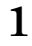

Received 7 August 2021

Revised 1 November 2021

3 November 2021

10 December 2021

Accepted 3 January 2022

\begin{abstract}
Purpose - This research aims to study the students' perspectives on synchronous and asynchronous learning during the COVID-19 Pandemic. Both synchronous and asynchronous learning approaches used in online education have positive and negative outcomes. Hence, the aim is to study online education's positive and negative consequences, reflecting sync and async approaches. This research followed a mixed research approach. The key stakeholders of this research are the Indian educational institutions and students.

Design/methodology/approach - This research collected data from the students undergoing synchronous and asynchronous learning amidst the COVID-19 Pandemic. The data were collected $(N=655)$ from various students taking online classes during the pandemic. A questionnaire survey was distributed to the students through online platforms to collect the data. In this research, the authors have collected data using simple random sampling, and the same has been used for data analysis using SPSS version 26 . The collected data were exposed to a factor analysis using a principal component analysis technique to reduce the vast dimensions.

Findings - The study findings show that synchronous learning is sometimes stressful, placing more responsibility on students mainly because of the increased screen time. At the same time, asynchronous learning allows the students to self-explore and research the topics assigned to them. Students also felt that asynchronous activities create a burden because of many written assignments to be submitted within a short period. Overall, the COVID-19 pandemic has been challenging for the students and the teachers. However, teachers have helped students to learn through digital platforms. The majority of the respondents opined that technological disruptions and death in the family circle had been significant reasons for not concentrating during online classes. However, the combination of synchronous and asynchronous learning has led to a balanced education.

Practical implications - Higher education has undergone multiple transformations in a short period (from March 2020, 2021 and beyond). Educational institutions underwent a rapid transition in remote teaching and learning in the initial stages. As time progressed, educational institutions did course navigation where they relooked into their course plans, syllabus and brought a structural change to match the pandemic requirements. Meanwhile, educational institutions slowly equipped themselves with infrastructure facilities to bring academic integrity. At present, educational institutions are ready to face the new normality without disrupting services to society.

Social implications - Educational institutions create intellectual capital, which is important for the development of the economy. In the light of COVID-19, there are new methods and approaches newly introduced or old methods and approaches, which are reimplemented, and these approaches always work for the benefit of the student community.

Originality/value - The authors collected data during the COVID-19 pandemic; it helped capture the students' experience about synchronous and asynchronous learning. Students and faculty members are newly
\end{abstract}

(C) Cassandra Jane Fernandez, Rachana Ramesh and Anand Shankar Raja Manivannan. Published in Asian Association of Open Universities Journal. Published by Emerald Publishing Limited. This article is published under the Creative Commons Attribution (CC BY 4.0) licence. Anyone may reproduce, distribute, translate and create derivative works of this article (for both commercial and non-commercial purposes), subject to full attribution to the original publication and authors. The full terms of this licence may be seen at http://creativecommons.org/licences/by/4.0/legalcode. 
AAOUJ 17,1

exposed to synchronous and asynchronous learning, and hence, it is essential to determine the outcome that will help many stakeholders.

Keywords Online education, COVID-19, Synchronous and asynchronous learning, Educational institutions, Student's perceptions

Paper type Research paper

\section{Introduction}

An intellectual asset is a part of intellectual capital, which helps in earning capabilities in the future. Higher education is an essential aspect of creating intellectual capital (Rosa and Jakubowska, 2014). The history of education goes back to civilization itself. In the distant past, India used to have the Gurukul system of education, where anyone who wants to study can go to the teacher's house and request the teacher to teach them. If a guru accepts them as students, they can stay in the guru's place to acquire education and help with home chores and activities. The guru would allow a student to learn everything they wanted to know, from learning Sanskrit to reading all Holy Scriptures and Mathematics to Metaphysics. Every country has its way of bringing about changes in education. In India, a cutting-edge education system was introduced, bringing English education into the system, where more emphasis is given to education in the English language. Teaching was confined inside the classroom in this education system, and educators' connection with nature disappeared. However, it paves the way for every child by providing fundamentals to all different subjects at the early stages. The education sector has seen tremendous changes in a couple of decades with the help of innovation in technology, which provides plenty of choices for scholars to investigate in any field of their choice (Shelke, 2018). A digital revolution created an enormous change in the education sector and made education more flexible than in the early stages. According to the World Economic Forum's Global Competitive study, Finland has the most well-developed education in the world (Dickinson, 2019). Though India has not been fully developed in means of infrastructural facilities and quality education, there are new policies and regulations such as the New Education Policy 2020 to enhance the quality of Indian educational system, says Freire-Garabal and Núnez (2020). Educational institutions trained their faculty members to follow and implement the fundamentals of hybrid teaching to create a new experience for the student communities in the post-lockdown. In the post-COVID-19 lockdowns, when educational institutions reopened, students were eager to experience the on-campus sessions. To better facilitate teaching-learning, educational institutions witnessed "Hybrid Pedagogy," a new method to use technology to create a better learning environment for students on-campus and for students on the online platforms at the same time. These hybrid sessions reduced the face time and allowed students to experience technology-enhanced activity for students outside of class. Faculty members were trained through different Quality Improvement Program and Faculty Development Programs to relook into certain components such as course design, course resources, teaching aids, grading instructions, nature of assignments and grading procedures and so on. There was a further progression from Hybrid Pedagogy to the "Synchronous and Asynchronous" learning style. Gathering students and teachers in a physical classroom to interact, exchange knowledge, capture on-time feedback and learn on a fixed schedule is called "Synchronous learning," which can happen through an online platform or offline platform. Asynchronous learning aims to reduce the burden of learning in a scheduled time and helps the students learn through recorded videos, webinars, podcasts, online training courses. The success of any online discussion requires both asynchronous and synchronous modes of learning. For the well-being of the students, a combination of (Synchronous and Asynchronous) learning has been facilitated. These teaching-learning strategies enhance development, increase the happiness quotient, embrace institutions' brand image and individual goals for a better society. When we probe into the evolution of education from the Gurukula system to the current hybrid pedagogy, teaching and learning have undergone multidimensional changes and 
outcomes. Moreover, the perception of the student community on Synchronous and Asynchronous learning has to be explored as it remains a research gap. The students' perception is critical to be explored because new teaching pedagogy in light of the COVID-19 pandemic is no more hypothetical than we are currently experiencing it. These predictors from the analyzed results will help the institution, teachers, students and all the connected stakeholders to frame new strategies and take decisions when required.

\subsection{An overview of synchronous and asynchronous learning}

Teachers and students join together in a common place in a real-time situation, which is known as synchronous learning. Moreover, Salmon (2013) says that synchronous learning is bounded with real-time interaction, which is collaborative. In addition, Teng et al. (2012) state that the synchronous learning is also facilitated on the virtual platform where collaborative learning takes place. The instructors interact with students through teleconferencing, live streaming, video conferencing, live chatting and so on. Development of software in recent days with new features such as the chat-box window, polling questions, live feedback, survey and so on has been highly useful for the faculty members and the student community (Hrastinski, 2008b), Media supports synchronous e-learning and allows faculties and students to interact with each other, say Murphy et al. (2011); Park and Bonk (2007). The advantages of synchronous learning are that students can ask questions, seek answers, get immediate feedback and share opinions and ideas in the class as the session proceeding will be real time. The few disadvantages of synchronous learning are it is stressful due to the rigid schedule and may be continuous where students will be seated before the computers for long hours (Pappas, 2015; Perveen, 2016). The synchronous learning may be disrupted due to low network, unstable Internet connection and may not help the students learn continuously. The instructor sets the learning path for the learners to acquire knowledge at their own pace and time, which sometimes may not be up to the expectations of the students. Especially during a pandemic, students undergo various personal issues and may not be able to take up the online classes as per the schedule given by the teacher. Henceforth, to get involved in synchronous learning, students and teachers must devote time and coordinate with each other. In addition, synchronous learning is sometimes not flexible (Teng et al., 2012; Perveen, 2016). Asynchronous learning style has been widely followed to avoid these issues and provide education in a flexible mode. The standard method used in asynchronous learning is through the prerecorded session, virtual library, social media platforms, online forums and so on (Malamed, 2011; Lin et al., 2012). The benefits of asynchronous learning are it offers a lot of flexibility for the learner to progress in their learning at their own pace and can access learning from any place and time. In support of this, Wind Kofoed (2020) says that asynchronous learning enables students to lean with flexibility in their own comfort zone. Moreover, students get an opportunity to learn with freedom and wisdom and do not have to completely depend on the instructor (Trach, 2018). Asynchronous learning is costeffective, where it does not require daily attention from the instructors (Lawless, 2020; Tucker, 2020). Since it is a self-guided module, students can work on the content themselves and avail their education at a minimal cost. Few demerits of asynchronous learning are students feel less connected to the instructors and create a sense of loneliness due to a lack of conversation with the instructors and peers. It would make students procrastinate their work due to a lack of supervision. Sometimes, students forget to complete their asynchronous activities assigned to them by the faculty members. In addition, faculty members have to send gentle reminders to the students and remind them to finish the work and submit the same for evaluation.

\subsection{Understanding synchronous and asynchronous learning in the light of the COVID-19 pandemic}

Learning methodology is divided into two distinct parts, known as the synchronous and asynchronous learning approaches. These learning approaches have become the most potent

Synchronous learning and asynchronous learning 
AAOUJ 17,1

4

learning methodologies, which creates a unique difference between traditional learning and e-learning (Hrastinski, 2008a). Synchronous learning is essential as it gives face-to-face tutoring and enhances students' attitudes and learning morale (Tsuei, 2012). Asynchronous learning enhances students' self-discipline and self-regulatory authority to learn and benefit (Vonderwell et al., 2007). Hence, this combination of Sync + Async = Balanced Learning has become the need of the hour and has allowed enjoying continuous education without disruptions (Picciano, 2009). Indian educational institutions are witnessing this combination for the first time in an in-depth way because $90 \%$ of importance was given only to the synchronous learning in the earlier stages of the COVID-19 pandemic. Sitting before the screens most of the time will negatively impact students' health. Educational institutions should consider a combination of synchronous and asynchronous learning that will benefit the students and the teachers during the pandemic (see Figure 1).

\subsection{Operationalizing the term "balanced learning"}

Advanced tools in online learning enable learners to adapt and personalize preferences in a learning environment. Three types of communication are essential to foster collaborative learning. Educational institutions should train faculty members who will help the students to learn and at the same time encourage students to engage in self-learning. Many research shows that on-campus learning will give students better exposure than online learning. However, to cope with the pandemic online education is safe and flexible. But the students should not feel overburdened in virtual education. Hence, there is a need for collaborative learning. Faculty members can encourage students to learn in small groups, which will help students learn and realize the importance of teamwork skills and traits. During the asynchronous hours, teachers can assign students group activities such as blog writing, content creation on YouTube, solving a case study and so on. Asynchronous activities need not be stand-alone work that has to be done by individual students. It can also be collaborative learning. However, the presence of the teacher will not be there; there are still many benefits for the student community. To facilitate learning, educational institutions can schedule synchronous classes, which will help the students interact and clear their doubts with the teachers. Henceforth, there should be a good combination of both. Synchronous learning and asynchronous learning are not just approaching to facilitate learning but also a communication strategy dealing with Knowledge Sharing (KS), Knowledge Acquisition (KA) and Knowledge Transfer (KT). There are different ways to perceive and understand synchronous and asynchronous learning, tools such as threaded discussion, blog and instant messages help in creating a classroom experience where communication is not only between instructor and learners but also among the learners themselves (Shahabadi and Uplane, 2015). Balanced learning is the process of exploring knowledge using digital tools, technology, which has instructor-based face-to-face learning, and instructor supervised learning without face-to-face learning. Hence, balanced learning is the outcome of sync and async learning in light of the COVID-19 pandemic. The same will be applicable even for a new normality situation in the post-COVID-19 pandemic. It is important to know if students were able to have a balanced learning experience.

Figure 1.

Showing the formula for a balanced learning approach

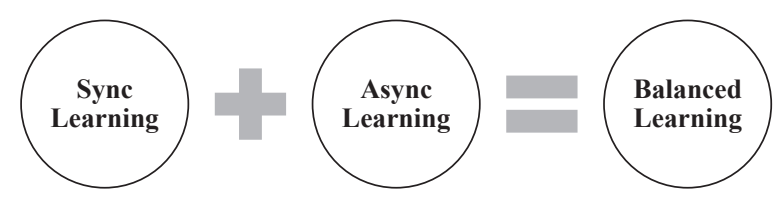




\section{Scope of the study}

The sudden pandemic outbreak has affected the educational sector, which stands as an essential determinant in producing intellectual assets for the growth and sustainability of a nation. Institutions are adopting new ways of learning to reduce the burden during online education. This research focuses on how synchronous and asynchronous approaches have created a shift in the education sector in this pandemic and also tries to introspect the various online learning options and platforms available for the student community to learn in the pandemic crisis. In this research, the researchers try to understand the positive and negative outcomes of synchronous and asynchronous learning and analyze students' experiences. The study will help us understand whether synchronous learning and asynchronous learning are student-friendly and understand whether students are ready to accept this new change introduced by educational institutions. Hence, this research confines exploring the synchronous and asynchronous learning approaches from the perspective of Indian students.

\section{Expected contributions from the study}

Globally, the impact of the COVID-19 crisis is a massive hit on educational institutions, and educational institutions have facilitated education on digital platforms. Not all students can buy laptops and have a broadband connection to take up online classes. The rural areas in India do not have basic infrastructural facilities. Henceforth, when the qualitative data were collected, it was evident that synchronous and asynchronous learning approaches were known only to those students living in the urban and township areas. Moreover, only a few universities have implemented such innovative teaching-learning pedagogy in the COVID-19 crisis. Through this research, a valid suggestion has been proposed to the Government of India to include the underprivileged children to receive free education and also distribute free electronic gadgets such as digital tablets and laptops and encourage them to learn without any disruptions. Moreover, since the balanced learning approach is new, higher educational institutions can train faculty members to use innovative and sensible teaching methods. Platforms such as SWAYAM, Coursera can provide free training courses on synchronous and asynchronous learning methodologies facilitated by professors and academicians of top institutions of the world.

\section{Theoretical underpinning}

From the view point of educational institutions, asynchronous activities are given to students to reduce their screen time and to give them more flexibility to complete different task at their own comfort zone. With an intention to make the students feel comfortable and to give them a personal space to self-learn and reflect on certain topics, asynchronous activities are planned by the teachers. On the other hand, there are few important topics that are handled by teachers with a personal touch. From the students; viewpoint, learning during the initial lockdowns was a dual task, that is, managing synchronous and asynchronous activities. Asynchronous activities gave space for the students to search, analyze, explore new knowledge. Synchronous learning gave them opportunity to acquire knowledge from their teachers during the virtual classes. However, the outcome of sync and async was based on exploration and exploitation. Hence, for the theoretical underpinning, the researchers have considered the individual ambidexterity theory. Perhaps it is important to know the underlying theme of the theory, which states that "The ability to simultaneously pursue both incremental and discontinuous innovation from hosting multiple contradictory structures, processes, and cultures within the same firm". When students are given activities, they involve themselves to transcend the boundaries of exploration and acquire knowledge, which becomes more meaningful. Sometimes, they lose focus and do not achieve the final goal; however, they exploit resources. Knowledge that they have acquired on exploiting and exploring resources will help them capitalize in future. This has been stated by
Synchronous

learning and asynchronous learning

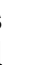


AAOUJ 17,1

6

Papachroni and Heracleous (2020) that there are three major elements in individual ambidexterity, that is, exceeding the boundaries of exploration and exploitation, accomplishment of dual task and benefitting by balancing between exploitation and exploration. As per the demands of the pandemic, there was a structural change in the way educational institutions functioned. However, balancing between exploration and exploitation depends on individuals' capacity and capabilities. Balancing between synchronous and asynchronous activities depends on individuals' capacity. The same has been mentioned by Gibson and Birkinshaw (2004) that it is left up to the individuals to balance between exploitation and exploration. This is more suitable for this research article because if a student knows the art of balance between synchronous and asynchronous learning, he/she may not find it to be a burden and can be very productive. On the other hand, if the art of balancing between synchronous and asynchronous is not known by the students, then the outcome may be negative.

\section{Review of literature on synchronous and asynchronous learning}

For online learning to become successful, educational institutions and organizations can adopt two systems: synchronous or asynchronous approaches. Synchronous learning occurs when all the participants interact at the same time. In contrast, asynchronous learning allows participants to exchange ideas and information without the dependency of other participants interacting simultaneously (Chauhan, 2017). There is a difference between synchronous and asynchronous online conversations (Malik et al., 2017). Teachers and students can establish a better connect and enhance communication effectively with the help of synchronous methods. Different spaces can be utilized to facilitate synchronous learning, say Moallem (2015), Barron et al. (2005). Synchronous learning has many advantages for the students, which include: motivation and participation, establishment of social relations, KT, KA. These added values are not experienced through asynchronous learning approach (Murphy et al., 2011). However, synchronous learning can be successful only when certain arrangements are done beforehand. The facilitators have to prepare the teaching materials, schedule the class time, take attendance, maintain the decorum and so on (Shukriet al., 2020). The efficacy of synchronous learning needs to be explored to know how well this model impacts online learning, what strategies are best suited for different students and what tools can provide better support for those particular strategies (Park and Bonk, 2007). On the other hand, the most flexible learning approach is asynchronous learning because there is no requirement for a face-to-face interaction in a real time. Teachers and the students are not present virtually or in any physical environment, but learning still happens in a successful manner. The teacher assigns activities and different tasks to the student and the same is done and submitted within a given time frame. Based on the work that has been submitted by the students, the teachers assess them (Carroll, 2011). Asynchronous learning develops the cognitive capacity and capabilities of the student as they take efforts to study by their own without depending on the teachers. In this process, they invest time and energy to search, research, learn and acquire knowledge. Hence, asynchronous learning makes the students more disciplined and exposed to vast knowledge (Shahabadi and Uplane, 2015; Plesec Gasparic and Pecar, 2016; Chauhan, 2017; Craig et al., 2016).

\section{Statement of the problem}

Indian educational institutions have suddenly adopted synchronous and asynchronous learning approach in the light of pandemic. Students and teachers had an increased screen time and could not hold face-to-face discussions more than a certain time span. Hence, teachers conduct activities and provide assignments, which are aligned to the subjects they teach. However, students have to strike a balance between synchronous and asynchronous activities, which is quite difficult. Most importantly, the demographics of the students play a very important role 
and have a significant impact on their education. Indian students differ from each other in terms of income capacity, family background, educational qualification, exposure to technology and digital tools, culture and so on. Thus, during the pandemic, few students who did not have the basic facilities such as the Internet connection and a personal computer found it highly challenging to complete the activities, which has increased stress. Few situations where students' family members or students themselves are affected with the COVID-19 virus had realtime challenge. For few, balanced learning approach was very flexible and has been much appreciated as they could finish the activities and assignments as per their comfort and also had time for their personal life. However, it is important to understand the perceptions of the students because their experiences will help the educational institutions frame better strategies for the future. Asynchronous activities assigned to the students are monitored by the faculty members and grades are also assigned; however, the completion of the task on-time, as per the instructions given by the teachers, is still questionable. There are also few students who did not consider asynchronous activities to be important. Self-study always gives an opportunity for students to learn something new as they have the space to research and find new knowledge. Asynchronous activities and assignments have a scope to explore and also exploit resources. If the resources are used in the right manner, students benefit out of it, and if they do not make use of it, they may not gain benefits. Hence, this ambidextrous approach has its own pros and cons, which are to be explored in this research.

\section{Research questions}

The research questions provide an orientation for investigation (Bryman, 2007). Framing a research question helps to investigate and seek answers to the questions. This research tries to investigate a few questions:

$R Q 1$. How has online education impacted the student community?

$R Q 2$. What are the students' expectations from the asynchronous and synchronous learning?

RQ3. How does asynchronous learning help students imbibe discipline in self-learning?

$R Q 4$. What are the various challenges faced by students when they take up live synchronous sessions?

RQ5. Are teachers and students prepared to balance between synchronous and asynchronous activities?

RQ6. Are students comfortable in taking online classes? Is online education better than traditional education?

RQ7. Do parents support students in taking up online classes?

$R Q 8$. What are the various technological devices used by students to take online classes?

RQ9. What are the few strategies to improvise synchronous classes?

$R Q 10$. Do students feel a sense of frustration and anxiety while attending synchronous and asynchronous classes?

\section{Research materials and methods}

This research collected data from the students undergoing synchronous and asynchronous learning amidst the pandemic. The data were collected $(N=655)$ from students during the pandemic time. A questionnaire survey was distributed to the students through online
Synchronous

learning and

asynchronous learning 
AAOUJ 17,1

platforms to collect the data. The questionnaire had students' general perception of synchronous and asynchronous learning. Key variables have been hand-picked after an in-depth literature review, and the same has been converted into question statements for construct the questionnaire. The response is received with a good spread of Likert's threepoint scale: (1) agree, (2) neutral and (3) disagree. This scaling option helps the researchers to obtain an adequate spread of responses. If the scaling options are extended beyond 5 or 7 , there are possibilities where the respondents can be biased. Henceforth, a Likert's three-point scale has been used. Data have been collected using a simple random sampling, and the same has been used for data analysis using SPSS version 26 . The collected data were exposed to a reliability test using Cronbach's alpha method. The reliability value is more than 0.7 , which is considerably good and accepted to proceed further. Moreover, the collected data are a reflection from the experiences of students during the lockdown, which had a good spread of responses. Thus, the data are normally distributed and project the transparency in data collection and the population from which the samples are drawn.

\section{Questionnaire development process}

The development of a questionnaire in social research is very crucial. Therefore, the following steps were taken to develop questions on these themes.

Step 1: Going through literature reviews to explore more about synchronous and asynchronous learning.

Step 2: Understanding the importance of synchronous and asynchronous learning from a different perspective through previous researchers' operational definitions and research knowledge.

Step 3: Screen and select a few relevant articles to help us seek answers for different research problems.

Step 4: Pick up the most appropriate statements from the selected article to construct question statements to collect data from respondents.

\section{Factor analysis}

Synchronous and asynchronous learning approaches adopted by educational institutions have positive and negative outcomes. The survey instrument is designed with positive and negative outcomes of asynchronous and synchronous learning. Every question statement used is a reflection of a synchronous or asynchronous learning approach. Since the number of dimensions was large, factor analysis has been used to reduce the same (Rummel, 1970). All the positive and negative statements were separately exposed to factor analysis using the principal component analysis technique. Before extracting components, the KMO and Bartlett's tests and their results were analyzed. KMO measures the sample adequacy, ranging from 0 to 1, where more than 0.5 is considered suitable, and Bartlett's test of sphericity indicates the significance of the data, which should be less than 0.05 . In this study, the negative and positive statements show KMO of 0.911 and 0.912 , respectively, which states that the factor variables are suitable, which suits the factor analysis (see Tables 1 and 2).

After extracting the components, it is necessary to interpret the factors with their factor loading, so the varimax rotation technique is applied. It minimizes the high loading variables to each factor and retains all the factors loading having more than 0.5. Based on the factor analysis output for negative statements (Table 3), the fundamental factors are grouped under five iterations, and a suitable name has been given. 
The name of component 1 is "Online classes are stressful."

The name of component 2 is "Insecurities and frustration."

The name of component 3 is "Places more responsibilities."

Based on the factor analysis output for positive statements (Table 4), the entire factors have been grouped under two iterations, and a suitable name is given. Two statements factor loading showed below 0.5 , so that statement was excluded.

The name of component 1 is "Student-centered and effective."

The name of component 2 is "Flexible and collaborative."

\section{Discussion}

Our study analyzes the students' perception of synchronous and asynchronous learning approaches represented in the form of positive and negative outcomes during the COVID-19 crisis. The data were collected from students taking up online classes. We received $N=655$ responses, out of which $59.7 \%$ were female, and $39.5 \%$ were male, where most of them were undergraduate students. Majority of the students range between the age of 17 and 21 doing their undergraduate programs in different educational institutions in India. From the analysis the researchers have understood that most of the students study in private institutions and are exposed to technology. This is because only few reputed educational institutions have introduced synchronous and asynchronous approach as a part of teaching and learning. Government institutions and few private institutions that have no technological exposure have not given importance to the balanced learning approach. Screening the gender status of the respondents, majority of the respondents were male $(65 \%)$ and remaining $(35 \%)$ were female respondents. Male gender dominates the female gender, and this may be because of the society and Indian demographic spread. Many males get an opportunity to pursue their higher education when compared to the females. Apart from these basic demographic questions, researchers have also captured information pertaining to respondent's experience
Synchronous

learning and

asynchronous learning

KMO and Bartlett's test

Bartlett's test of sphericity

$\mathrm{KMO}$ and Bartlett's test 


\section{AAOUJ 17,1}

Rotated component matrix

Rotated component matrix

I think face-to-face classes are better than online classes (S)

Online classes placed too much of a burden on you (S)

I have faced the problem of slow network and technical difficulties during online classes (S)

I think sharing of knowledge is limited in online classes (S)

I think my education is affected due to a lack of face-to-face interaction with the lecturer, and I am not able to clear my doubts (A)

Students with poor monitoring issues struggle while learning online (S)

It is difficult to coordinate group tasks with your group members due to the differences in location and time (A)

I delay my task because, basically, I do not clearly understand what has been taught to me (A)

My motivation and academic performance are decreased due to limited

interaction and lack of campus experience ( $\mathrm{S} \& \mathrm{~A})$

Online classes create a sense of loneliness as I am not able to interact with my

friends (S \&A)

I have faced difficulties while trying to contact the instructor for help or to clear my doubts (S \&A)

I have experienced insecurities while trying to message in an online class (S)

I feel a sense of frustration when my questions are not answered immediately by the tutor $(\mathrm{S})$

I am not able to understand the concept during online lectures (S)

Online classes have placed more responsibilities in the COVID-19 pandemic (S \& A)

Table 3.

Rotated component matrix for data about negative statements
Note(s): Extraction method: Principal component analysis

Rotation method: Varimax with Kaiser normalization

${ }^{\text {a }}$ Rotation converged in five iterations

during the pandemic. From the percentage analysis, researchers understood that almost $69.8 \%$ of the students never experienced online classes before the COVID-19 crisis, which helped to come to the opinion that the COVID-19 pandemic made students take up online classes. According to the students' most commonly used technology to take up, online classes were through mobile phones, where they opined network connectivity was quite good to attend classes. Almost 78\% of parents also supported them to take up online classes. There were quite a few responses such as financial issues, technical problems, health issues and prioritizing family commitments that restrained parents from supporting their wards in taking online classes. Our study also raised open-ended questions to know more about synchronous and asynchronous learning approach. From the analysis and from the openended questions, researchers have received mixed responses. Few responses are highly supportive to the online education as they say online education is flexible, saves times and effective. On the other hand, few respondents say that online education is not flexible as it places responsibilities, creates stress and is causes insecurities among students. Few students observed that teachers failed to give attention to slow learners, who fall under the visually impaired, speech impaired and hearing-impaired category. In addition, they also said that teachers need to plan activities and need to undergo special training to break work into smaller chunks and deliver the same to the students with more clarity. Thus, teachers need to prepare themselves to balance learning activities. Our study also has questions related to MOOC courses, which have become very popular in the COVID-19 pandemic. Researchers asked questions related to MOOCs to know the opinion of the student communities. From 
Rotated component matrix

Question statements

Online classes are as effective as face-to-face classes (S)

I think an online environment is a student-centered approach (S)

Online classes help in generating new perspectives (S)

Online classes are cost-effective, and a replacement for face-to-face courses and helps in saving different expenses such as travel, canteen, etc. (S)

Online learning provides an opportunity to develop skills and confidence in problem-solving (S)

Online learning provides an opportunity to compare, discuss and modify concepts (S)

Online classes are a better medium for education due to their flexibility (S)

The interaction between students and lecturers is better in online classes $(\mathrm{S})$

Online classes are a boon for continuous education in the COVID-19 pandemic without any disruptions (S)

I think collaboration with learners in an online class will improve critical thinking skills and help me brainstorm (S)

I am capable of taking responsibility for my learning in an online environment as I get an opportunity to self-explore (A)

Students who are shy or lack confidence are comfortable participating in an online class (S)

Online learning helps in arriving at general conclusions when there are differences in opinion (S)

Online classes can cater to more prominent participants as there is no constrain of time or space and is super flexible ( $\mathrm{S} \& \mathrm{~A})$
Synchronous

learning and asynchronous learning

$0.782 \quad 0.085$

$0.753 \quad 0.138$

$0.668 \quad 0.286$

$0.616 \quad 0.207$

$0.611 \quad 0.284$

$0.594 \quad 0.302$

$0.469 \quad 0.467$

$0.432 \quad 0.396$

$0.135 \quad 0.685$

$0.240 \quad 0.679$

$0.196 \quad 0.636$

$0.155 \quad 0.628$

$0.287 \quad 0.608$

$0.176 \quad 0.567$
Table 4.

Rotated component matrix for data about positive statements

their responses, researchers understood that the five most commonly used e-learning platforms in India were Coursera, Udemy, Khan Academy, Edx and Byju, where $51.1 \%$ chose Coursera over other platforms to take up MOOC courses. They also chose e-learning platforms such as MyCaptain, FutureLearn, Internshala, Upgrade and so on to learn courses online. MOOCs are also a part of the asynchronous approach where students self-explore and self-learn without depending on the tutor. Since few questions were multiple response questions, researchers analyzed it by defining the multiple response sets and running a frequency to know the percentage of student's responses. The majority of the students prefer asynchronous learning over synchronous learning due to several reasons. According to students, asynchronous learning helped them to self-motivate themselves where they used research skills to explore and understand a concept in a disciplined manner.

\section{Conclusion}

The impact of COVID-19 has created a massive imbalance in all sectors. The worldwide closure of educational institutions has an impact on student's academic life. The outburst of COVID-19 has taught everyone that change is necessary and forced educational institutions to adapt to the new technology, which was not used frequently before the pandemic (Jena Kumar, 2020). Online learning now serves as a new panacea during this crisis (Dhawan, 2020). The findings from the study stated that the outcome of online classes (synchronous and asynchronous) is quite stressful, which placed more responsibilities and created a kind of frustration and insecurities among students. Simultaneously, online classes are studentcentric, which provides more flexibility for students to work collaboratively to increase class effectiveness. Thus, researchers have received mixed opinions and feedbacks from the students. Researchers have to conclude saying that all educational institutions are taking their maximum and best efforts for the benefit of the students. Students have to understand 
AAOUJ 17,1

these efforts and should equally work hard to achieve success. Both synchronous and asynchronous approaches have their own pros and cons. However, students have to strike a balance between sync and async classes. India being a developing economy has not fully witnessed technological development, where few rural areas do not have any access to basic online education. The concept of synchronous and asynchronous learning approach is very new and needs more clarity. Henceforth, in the upcoming days, there should be a balance between both approaches. Future researchers have many opportunities and scope; however, synchronous learning is progressing smoothly, it is also important to motivate students to get involved with asynchronous activities and tasks. In addition, future research can be done on teachers' perspectives on online education because it is equally important to study teachers' mentality during the pandemic. These aspects need to be explored to make online classes more effective and productive during this pandemic. Suggestions such as free Internet and better connectivity are concerns raised by students that the government can look into and provide solutions for the same. Researchers can construct new policies and regulatory models that will help the government frame strategic policies for the educational institutions.

\section{References}

Barron, A.E., Schullo, S., Kromrey, J.D., Hogarty, K.Y., Venable, M., Hilbelink, A., Barros, C., Loggie, K., A. and Hohlfeld, T. (2005), "Synchronous E-learning: analyzing teaching strategies", Proceedings of Society for Information Technology and Teacher Education International Conference, pp. 3060-3067.

Bryman, A. (2007), "The research question in social research: what is its role?", International Journal of Social Research Methodology, Vol. 10 No. 1, pp. 5-20, doi: 10.1080/13645570600655282.

Carroll, N. (2011), "Evaluating online asynchronous support in the institutes of technology Ireland", All Ireland Journal of Higher Education, Vol. 3 No. 2, pp. 1-23.

Chauhan, V. (2017), "Synchronous and asynchronous learning”, Imperial Journal of Interdiciplinary Research, Vol. 3 No. 2, pp. 1345-1348.

Craig, C., Black, D.R., Aaltonen, P.M., Kirby, A. and Dietz, J.E. (2016), "Examining the difference between asynchronous and synchronous training", IMSCI 2016-10th International MultiConference on Society, Cybernetics and Informatics, Proceedings, pp. 241-246.

Dhawan, S. (2020), "Online learning: a panacea in the time of COVID-19 crisis", Journal of Educational Technology Systems, Vol. 49 No. 1, pp. 5-22, doi: 10.1177/0047239520934018.

Dickinson, K. (2019), How does Finland's Top-Ranking Education System Work? Big Think, available at: https://www.weforum.org/agenda/2019/02/how-does-finland-s-top-ranking-educationsystem-work.

Freire-Garabal, M. and Núñez, M. (2020), "Practical recommendations to the new education policy of India 2020", Al-Khalifa Business School Education Journal. doi: 10.21428/2efc4e67.19584a7f.

Gibson, C.B. and Birkinshaw, J. (2004), "The antecedents, consequences, and mediating role of organizational ambidexterity”, Academy of Management Journal. doi: 10.2307/20159573.

Hrastinski, S. (2008a), “Asynchronous and synchronous E-learning”, EDUCAUSE Quarterly.

Hrastinski, S. (2008b), “Asynchronous and Synchronous E-learning”, EDUCAUSE Review.

Jena Kumar, P. (2020), "Impact of pandemic COVID-19 on education in India”, International Journal of Current Research, Vol. 12 No. 7.

Lawless, C. (2020), "Synchronous vs. Asynchronous learning: which is right for your learners?", available at: https://www.learnupon.com/blog/synchronous-learning-asynchronous-learning/.

Lin, H.S., Hong, Z.R. and Lawrenz, F. (2012), "Promoting and scaffolding argumentation through reflective asynchronous discussions", Computers and Education. doi: 10.1016/j.compedu.2012. 01.019 . 
Malamed, C. (2011), "Synchronous and asynchronous learning explained virtual classroom learning or self-paced instruction?", available at: https://theelearningcoach.com/elearning_design/group-orself-paced-instruction/.

Malik, M., Fatima, G., Hussain, C.A. and Sarwar, A. (2017), "E-learning: students' perspectives about asynchronous and synchronous resources at the higher education level", Bulletin of Education and Research, Vol. 39 No. 2, pp. 183-195.

Moallem, M. (2015), "The impact of synchronous and asynchronous communication tools on learner self-regulation, social presence, immediacy, intimacy, and satisfaction in collaborative online learning", The Online Journal of Distance Education and E-Learning, Vol. 3 No. 3, pp. 53-77.

Murphy, E., Rodríguez-Manzanares, M.A. and Barbour, M. (2011), “Asynchronous and synchronous online teaching: perspectives of Canadian high school distance education teachers", British Journal of Educational Technology, Vol. 42 No. 4, pp. 583-591, doi: 10.1111/j.1467-8535.2010. 01112.x.

Papachroni, A. and Heracleous, L. (2020), "Ambidexterity as practice: individual ambidexterity through paradoxical practices", Journal of Applied Behavioral Science. doi: 10.1177/ 0021886320913048.

Pappas, C. (2015), Synchronous Learning Advantages and Disadvantages in Corporate Training, available at: https://elearningindustry.com/asynchronous-learning-advantages-anddisadvantages-in-corporate-training.

Park, Y.J. and Bonk, C.J. (2007), "Is online life a breeze? A case study for promoting synchronous learning", MERLOT Journal of Online Learning and Teaching, Vol. 3 No. 3, pp. 307-323.

Perveen, A. (2016), "Synchronous and asynchronous E-language learning: a case study of virtual university of Pakistan", Open Praxis, Vol. 8 No. 1, pp. 21-39, doi: 10.5944/openpraxis.8.1.212.

Picciano, A.G. (2009), "Blending with purpose: the multimodal model", Journal of Asynchronous Learning Network. doi: 10.24059/olj.v13i1.1673.

Plesec Gasparic, R. and Pecar, M. (2016), "Analysis of an asynchronous online discussion as a supportive model for peer collaboration and reflection in teacher education", Journal of Information Technology Education: Research, Vol. 15, pp. 369-393.

Rosa, A. and Jakubowska, A. (2014), "Significance of higher education in creating of intellectual capital", Human Resources Management and Ergonomics, Vol. 8 No. 2.

Rummel, R. (1970), Factor Analysis.

Salmon, G. (2013), E-tivities: The Key to Active Online Learning.

Shahabadi, M.M. and Uplane, M. (2015), "Synchronous and asynchronous e-learning styles and academic performance of e-learners", Procedia - Social and Behavioral Sciences, Vol. 176, pp. 129-138, doi: 10.1016/j.sbspro.2015.01.453.

Shelke, T. (2018), To Study the Impact of Innovations in Education, Vol. 4 No. 3, pp. 10-12.

Shukri, A., Nordin, L., Salleh, F.I.M., Raidzwan, S.N.M. and Ahmad, R. (2020), "UniKL students' perception on synchronous learning using ICT as learning tools to learn English", Journal of Critical Reviews, Vol. 7 No. 8, pp. 793-796, doi: 10.31838/jcr.07.08.170.

Teng, D.C.E., Chen, N.S., Kinshuk and Leo, T. (2012), "Exploring students' learning experience in an international online research seminar in the Synchronous Cyber Classroom", Computers and Education. doi: 10.1016/j.compedu.2011.10.018.

Trach, E. (2018), Asynchronous Learning: Definition, Benefits, and Example Activities.

Tsuei, M. (2012), "Using synchronous peer tutoring system to promote elementary students' learning in mathematics", Computers and Education. doi: 10.1016/j.compedu.2011.11.025.

Tucker, C. (2020), Asynchronous vs. Synchronous: How to Design for Each Type of Learning, available at: https://catlintucker.com/2020/08/asynchronous-vs-synchronous/. 
AAOUJ 17,1

\section{4}

\section{Corresponding author}

Cassandra Jane Fernandez can be contacted at: cassandra.f@mcom.christuniversity.in online learning”, Journal of Research on Technology in Education. doi: 10.1080/15391523.2007. 10782485.

Wind Kofoed, D. (2020), "Synchronous vs asynchronous learning: what's more effective?", available at: https:/www.eduflow.com/blog/synchronous-vs-asynchronous-learning-whats-more-effective.

\footnotetext{
For instructions on how to order reprints of this article, please visit our website: www.emeraldgrouppublishing.com/licensing/reprints.htm Or contact us for further details: permissions@emeraldinsight.com
} 